\title{
La Tragedia como fundamento estructural de "La Hojarasca"
}

POr PEDRO LASTRA

En un agudo examen de La vorágine como un viaje al país de los muertos, Leonidas Morales se refirió a las posibilida. des que podría tẻnerentrecinosótrosin un muevo tipo de investigación, fundado en el análisis de ciertos tópicos y motivos -en parte, incluso, al margen de la tradición europea-, que en algunas importantes narraciones hispanoamericanas funcionan como correlatos de comprensión que permiten integrar y hacer inteligible el sentido último de esas creaciones $\left({ }^{1}\right)$. A las obras citadas por Leonidas Morales, además de La vorágine (Los pasos perdidos, de Alejo Carpentier y El Señor Presiden. te, de Miguel Angel Asturias), habría que agregar La hojaras$c a$, primera novela del escritor colombiano Gabriel García Márquez (n. 1928), publicada en $1955\left({ }^{2}\right)$.

No conocemos ningún trabajo crítico dedicado a La hojarasca que atienda al sentido esclarecedor del epígrafe que Gabriel García Márquez pone al comienzo de su novela. Se trata de una cita de Antigona, de Sófocles, que corresponde

\footnotetext{
(1) Leonidas Morales. "La voragine: un viaic al pais de los muertos". En Anales de la Universldad de Chile. Año CXXIII. No 134, abril-iunio de 1965. pp. 148-170. Cf. pp.

(2) 158-159 y. particularmente. pp. 169-i70.

(2) La hojarasca. (Novela). Bogotá-Colombia, Ediciones - S.L.B., 1955. 137 p.
} 
al momento en que Antígona comunica a Ismena la determinación de Creonte acerca de los funerales de Eteocles y de Polinices:

Y respecto del cadáver de Polinices, que miserablemente ha muerto, dicen que ha publicado un bando para que ningún ciudadano lo entierre ni lo llore, sino que insepulto y sin los honores del llanto, lo dejen para sabrosa presa de las aves que se abalancen a devorarlo. Ese bando dicen que el bueno de Creonte ha hecho pregonar por ti y por mí, quiere decir que por mi; y que vendrá aquí para anunciar esa orden a los que no la conocen; y que la cosa se ha de tomar no de cualquier manera, porque quien se atreva a hacer algo de lo que prohibe será lapidado por el pueblo. (3)

El único crítico que se detiene brevemente a considerar el epígrafe es Luis Harss, pero ve en él un simple comentario irónico de la situación: "Y así, como Polinices, perecerá el doctor, pero no su recuerdo, ni todas las pasiones que dejó atrás, que seguirán rondando como un castigo por el pueblo" $\left({ }^{4}\right)$.

Para nosotros, en cambio, esa cita de Antigona es reveladora, en la medida en que el paralelismo de las situaciones planteadas en la tragedia de Sófocles y en la novela de García Márquez permite ver esta última como un intento de desarrollo, sutilmente elaborado, de la visión trágica de un presente social concreto, que llena de patetismo - al hacerla comprensiva- una expresion literarial que se proyecta en el hecho histórico que conocemos hoy bajo la denominación sociológica de la "violencia colombiana" $\left({ }^{5}\right)$. Aunque el acontecimiento central de la novela ocurre en 1928, es evidente que la "violencia" constituye la base de contenidos objetivos inmediatos que el autor aprehende aquí en su dimensión trágica.

Desplegar esa dimensión de lo trágico en La hojarasca supone, necesariamente, una inteligencia clara del fundamento proporcionado por la tradición literaria, que aquí ha sido ac-

(3) Hemos consultado varias ediciones de las Tragedias de Súfocles. Para las citas que siguen, nos atenemos a la traducción de J. Alemany Bolufer (Sofocles. Tragedins. Prólogo de Félix F. Corso. Madrid-Buenos Aires, Librería Perlado Editores, 1944), cuya lectura cor:esponde, casi cabalmente, al texto del epigrafe elegido por García Márquez. Las demás traducciones difiezen en mayor o menor grado, en matices de interpretación del original griego.

(4) Luis Harss. "Gabriel García Márquez, o la cuerda floja". En Los nuestros. Buenos Aires.Editorial Sudamericana, 1966. Vid. p. 396.

(5) Sobre este tema, véase la impresionante investigación realizada por Mons. Germán Guzmán Campos, Orlando Fals Borda y Eduardo Umaña Luna: La violencia en Co. lombin. Estudio de un Proceso Social. Bosotá, Colombia, Ediciones Tercer Mundo, Tomo I, Segunda edición, 1962. 430 p.; Tomo II, 460 p. 
tualizado y, en más de un momento, alterado o fundido, de acuerdo con las exigencias de una estructura particular - la de la novela que examinamos-, a través de la cual el novelista quiso expresar su percepción de la realidad.

Desde luego, debemos señalar que La hojarasca no nos parece una obra absolutamente lograda, a pesar de la eficacia con que García Márquez utiliza el esquema de la tragedia y del rigor y la belleza de su lenguaje. Lo que atenta contra su perfección es la prisa con que el escritor se enfrentó a ciertos problemas formales: el punto de vista triple a que recurre, por ejemplo, requería una diferenciación convincente de cada personaje. El viejo coronel, la mujer y el niño que asisten como testigos y realizadores del acto de sepultación del cadáver del médico suicida, condenado por el pueblo a pudrirse detrás de las paredes de su casa, y cuya historia es la que se reconstruye a través de los monólogos, hablaṇ con una voz indistinta. "Como no hay intimidad en los monólogos -apunta Harss-, el resultado no es la densidad sino la monotonía" (Los nuestros, p. 397)

Otros desniveles de la obra, observados en más de una nota crítica $\left({ }^{6}\right)$, son imputables a la impericia juvenil, a la adhesión, tal vez excesiva, al sistema narrativo faulkneriano, etc. Pero nuestra tentativa, por ahora, se limita a proponer un análisis que revele en La hojarasca la visión de la realidad histórico-social colombiana dedeste siglà percibida como trágica y configurada en un contexto en el que han sido asumidos elementos y motivos de la más antigua y prestigiosa tradición literaria $\left({ }^{7}\right)$.

(6) Véase, al final de este trabajo, la bibliografía que hemos preparado.

(7) Gilbert Highet ha estudiado detalladamente la influencia clásica en las literaturas de la Europa occidental y de los Estados Unidos, en su memorable investigación titulada La tradictón clásica (1949). Traducción española de Antonio Alatorre. México-Buenos Aires, Fondo de Cultura Ecońsmica, 1954. (Lengua y Estudios Literarios). 2 vols. Los "capítulos XXII y XXIII de esta obra - "Los poetas simbolistas y James Joyce" y "La reinterpretación de los mitos"- son particularmente iluminadores de la prevalencia de diversos elementos de la tradición clásica en la literatura contemporánea, en el caso de autores "que cuentan y reinterpi-etan los mitos griegos en forma drámas o relatos. dándoles a veces un ambiente moderno pero casi siempre conservando cl antiguo escenario y los antiguos personaies" (t. II, p. 338). En este punto, la investigación de Highet parte de la consideracién de situaciones reconocibles en las obras como elaboraciones de esos mitos. Nos parcec ver una dirección distinta del cido tema en la pnsición adontada por T. S. F.liot al concrbi- Cocktail Partv. Conven. cido de que uno de los defectos mavores de Reunión de familla era "la falta de conbir Cocktre la historia gricga v la situación moderna". e inclinado todavfa - al escri"tomarlo simnlement a buscar su tema cn un dramaturso eriego. señala que decidió que nadie simnlemente como punto de pa-tida", y disimular sus orisenes de tal manera menns, he teniera identificarlos mientras no los descubriese el mismo: "En esto, al ció las fuentes de exitn. Pues nadic. aue vo sena $-v$ ningnín crítico teatral- reconoen detallates de mi historia en el Alcestes de Eurípides. Tuve, en effeto. nue entrar trama de ecta cxplicaciones nara convenrer a duirnes estahan familiarizados con la mienzo se sintioron de la artenticidad de su inspiración. Y aquellos oue en un co. cido, ante su aparente intedidns ante la excéntrica conducta de mi huésned descono- 


\section{CORRESPONDENCIAS ENTRE LOS MOTIVOS FUNDAMENTALES DE "LA HOJARASCA" Y LAS TRAGEDIAS DE SOFOCLES}

1. Formulación de una promesa, cuyo cumplimiento tendrá consecuencias dramáticas o fatales.

Hacia el final de Edipo en Colono, Polinices obtiene la promesa de Antígona de que le tributará honras fúnebres a su muerte. Polinices, herido por la imprecación paterna, dice a Antigona y a Ismena:

¡Oh, niñas, hermanas mías! A vosotras pues, ya que habéis oído la crueldad del padre que asi me maldice, os ruego por los dioses que si las maldiciones del padre se cumplen y vosotras volvéis de algún modo a la patria no me menospreciéis, sino sepultadme y celebrad mis funerales; que vuestra gloria de ahora, la que tenéis por las penas que pasáis por este hombre, se acrecentará con otra no menor por la asistencia que me prestéis. (8)

La correspondencia de esta situación en La hojarasca se da en el compromiso que contrae el coronel con el médico, cuando éste, tres años antes de su suicidio, le salva la vida. Monologa el coronel:

Yo habia de préguntarle dos días después cuál era mi deuda, y él había de responder: "Usted no me debe nada, coronel. Pero si quiere hacerme un favor, écheme encima un poco de tierra cuando amanezca tieso. Es lo único que necesito para que no me coman los gallinazos".

En el mismo compromiso que me hacía contraer, en la manera de proponerlo, en el ritmo de sus pisadas sobre las baldosas del cuarto, se advertía que este hombre había empezado a morir desde mucho tiempo atrás, aunque habían de transcurrir aún tres años antes de que esa muerte aplazada y defectuosa se realizara por completo. Ese día ha sido el de hoy. $\mathrm{Y}$ hasta creo que no habría tenido necesidad de la soga. Un ligero soplo habría bastado para extinguir el último rescoldo de vida que quedaba en sus duros ojos ama-

algún consuelo después que hube llamado su atención hacia el comportamiento de Heracles en la obra de Eurípides". (Poesia y drama. Traducción de Ja:ge Zalamea. Buenos Aires, Emecé Editores, S.A., 1952. p. 46 y 48). En cl Prefacio a su traducción de Cocktall Party, Miguel Alfredo Olivera puntualiza la relación entre la obra griega y la de Eliot. Cf. Cocktail Party. Buenos Aires, Emecé Editores, S.A., 1950 p.11.

En un plano semeiante al indicado por Eliot se nos aparece el propósito narrativo de Gabriel García Márquez en La hojarasca.

(8) Sófocles. Edipo en Colono. Edit. cit., pp. 165-166. 
rillos. Yo habia presentido todo eso desde la noche en que hablé con él en el cuartito, antes de que se viniera a vivir con Meme. Asi que cuando me hizo contraer el compromiso que ahora voy a cumplir, no me sentí desconcertado. Sencillamente le dije:

-Es una petición innecesaria, cloctor Usted me conoce y debia saber que yo lo habría enterrado por encima de la cabeza de todo el mumdo, aunque no le clebiera la vida.

Y él sonriente, por primera vez apaciguados su duros, ojos amarillos:

- Todo eso es cierto, coronel. Pero no olvide que un muerto no habria podido enterrarme. (9)

\section{La condenación.}

La condenación de Polinices se decreta a su muerte, cuando éste cae luchando contra su hemmano Eteocles, defensor de Tebas, a la que ataca el ejéreito argivo comandado por aquél. Creonte, promovido al reinado de Tebas, determina que Eteocles, héroe de la ciudad, sea inhumado gloriosamente. Polinices, que ha invadido la tierra natal, no tendrá sepultura en ella. Su cuerpo, arrojado fuera de las murallas, servirá de alimento a perros y aves de rapiña. Dice Antígona a Ismena:

¿Pues no ha dispuesto Creonte que, de nuestros dos hermanos, se le hagan a uno las honras fúnebres y se deje al otro insepulto? A Eteocles, según dicen, en cumplimeinto de la ley divina y humana, sepultó en tierra para que obtenga todos los honores, allá bajo, entre los muertos. Y respecto de cadáver de Polinices, que miserablemente ha muerto, etc. (Cf. Supra, la cita recogida como epígrafe en La hojarasca).

(9) La hojarasca. Edit. cit. p. 131. En Mientras agonizo, de William Faulkner, el cumplimiento de una promesa constituye también el núcleo de la situación desencadenante. Las peripecias del fúnebre viaie hacia Jefferson tienen su otigen en la decisión de Anse de cumplir la promesa hecha a su esposa: "Estaría impaciente por llegar al cementerio ese de los suyos, el de Jefferson, donde tantos de su misma sangre la esperan. Le prometí que yo y los chicos la llevaríamos allá todo lo aprisa que las mulas caminen, de fo-ma y manera que puedá descansar tranquila" (Mientras agonlzo. Madrid, Aguilar, 1957. p. 36). Aunque la situacién que se desarrolla en la novela de Faulkner es desolada y dramática, no tiene la terribilidad de la tragedia, en la que Antígona es lapidada por cumplir el compromiso contraido con Polinices; en La hojarasca, la actitud del coronel tend:á consccuencias imprevisibles. Recuérdese que la novela concluye en el momento en que el cadáver del médico va a ser conducido al cementerio por aquél, desafiando la voluntad del pueblo. Se trata, por lo tanto, de un has abierto, que apunta a la violencia de una reacción más que probable de los habitantes contra el coronel y sus escasos acompañantes. No es la única vez que tudiar el cedimiento aparece en la obra de García Márquez. Luis Herss lo describe al esde una imagen La siesta del martes, cuando anota que el relato vive en la sugerencia omitido está ie algo que no ha sucedido todavia"... de algún modo lo que fue

omitido está implícito" (Los nuestros, p. 404). 
Y Antígona continúa:

Ya sabes lo que hay, y pronto podrás demostrar si eres de sangre noble o una cobarde que desdice de la nobleza de sus padres.

Ismena.- ¿Y qué? ¡Oh desdichada!, si las cosas están así, ¿podré remediar yo, tanto si desobedezco como si acato a esas órdenes?

Antígona.- Si me acompañarás ỳ me ayudarás, es lo que has de pensar.

Ismena.- ¿En qué empresa? ¿Qué es lo que piensas?

Antígona.- Si vendrás conmigo a levantar el cadáver.

Ismena.- ¿Piensas sepultarlo, a pesar de haberlo prohibido a toda la ciuclad?

Antígona.-A mi hermano, y no al tuyo, si tú no quieres; pues nunca dirán de mí que lo he abandonado.

Ismena.- ¡Oh desdichada! ¿Habiéndolo prohibido Creonte?

Antígona.- Ningún derecho tiene a privarme de los míos. (10)

"A fin de comprender la abnegación de Antígona - dice Paul de Saint-Victor-, conviene tener en cuenta las ideas que se abrigan en la antigüedad respecto a la sepultura. Esta era, entonces, el verdaderolfinedel hombre, el fondo estrecho e inmutable de su poryenir La salvación, en el sentido religioso de la palabra, dependia de la observancia de sus ritos.- Ser enterrado o no serlo era el problema de la vida futura" (11). La privación de la sepultura equivalía, pues, a una condenación, y no se imponía sino a los criminales más odiosos, a los traidores a la patria y a los asesinos. Era sacrilegio execrable dejar sin sepultura el cadáver de un ciudadano.

Aunque la concepción cristiana -específicamente la católica- excluye de honras fúnebres a los suicidas, en La hojarasca el alcance de la condenación adquiere otra dimensión de terribilidad, de signo eminentemente trágico. El pueblo de Macondo espera que el médico se pudra dentro de su casa, sin que nadie se preste siquiera para sepultarlo.

(10) Sófocles. Antígona..Edit. cit., pp. 177-178.

(11) Paul de Saint-Victor. Las dos carátulas, Historia del teatro griego y de las grandes épocas del arte teatral. Buenos Aires, Editorial "El Ateneo", 1552. 2 vols Vid. Tomo I, p. 466 . 
La sentencia condenatoria del pueblo contra el médico ha sido dicțada hace diez años. Recuerda el coronel:

Porque la noche en que pusieron las cuatro damajuanas de aguardiente en la plaza, y Macondo fue un pueblo atropellado por un grupo de bárbaros armados; un pueblo empavorecido que enterraba sus muertos en la fosa común, alguien debió de recordar que en esta esquina había un médico. Entonces fue cuancio pusieron las parihuelas contra la puerta, y le gritaron (porque no abrió; habló descle aclentro); le gritaron: "Docior, atienda a estos heridos que ya los otros médicos no dan abasto", y él responclió: "Llévenlos a otra parte, yo no sé nada de esto"; y le dijeron: "Usted es el único médico que nos queda. Tiene que hacer una obra de caridad"; y él respondió (y tampoco abrió la puerta), imaginado por la turbamulta en la mitad de la sala, la lámpara en alto, iluminados los duros ojos amarillos: "Se me olvidó todo lo que sabia de eso. Llévenlos a otra parte" y siguió (porque la puerta no se abrió jamás) con la puerta cerrada, mientras hombres y mujeres de Macondo agonizaban frente a ella. La multitud habría sido capaz de todo esa noche. Se disponían a incendiar la casa y reducir a cenizas a su único habitante. Pero en esas apareció El Cachorro. Dicen que fue como si hubiera estado aquí invisible, montando guardia para evitar la destrucción de la casa y el hombre. "Naclie tocará esta puerta", dicen que dijo El Cachorro. Y dicen que fue eso toclo lo que dijo, abierto en cruz, ituminado por el resplandor de la furia rural su inexpresivo y frío rostro de calavera de vaca. Y entonces el impulso se refrenó, cambió de curso, pero tuvo aún la fuerza suficiente para que gritaran esa sentencia que aseguraria, para todos los siglos, el advenimiento de este miércoles. (12) tuación:

Con anterioridad, el coronel ha rememorado la misma si...mientras el rencor crecía, se ramificaba, se convertía en una virulencia colectiva, que no daría tregua a Macondo en el resto de su vida para que en cada oído siguiera retumbando la sentencia - gritada esa noche- que condenó al doctor a pudrirse detrás de estas paredes. (13)

La condenación del médico que ha defraudado la invocación del pueblo, traicionando un principio de solidaridad, por

(12) La hojarasca. Edit. cit. pp. 129-130.
(13) Ibidem, p. 26 . 
lo que se ha hecho acreedor al odio colectivo, repite en más de un sentido la condenación de Polinices por su acto de rebelión contra la Ciudad.

Estos son los motivos que estimamos como principales en La hojarasca, y cuyo correlato es el de las dos citadas tragedias de Sófocles, especialmente Antígona. Pero aún es posible establecer otras relaciones muy claras.

\section{ACTITUD DE LOS PERSONAJES}

1.- El carácter de Antígona es inflexible. "Este corazón todo ternura — scñala Saint-Victor- se envuelve en el deber como en una triple coraza de bronce. Inaccesible al miedo, no admite que lo sientan los demás; su energía no concibe disculpas para la flaqueza. En este aspecto, una línea de rigidez la dibuja, parecida al trazo duro y puro que describe en silueta a las figuras trágicas representadas en los vasos griegos". $\left({ }^{14}\right)$ De ahí sus reproches a Ismena, que se siente incapaz de obrar contra la voluntad de los ciudadanos - representados por el Coro-, cuya voz mayor es la de Creonte. Nada la detendrá en su decisión de arrostrar la muerte por cumplir la promesa formulada a Polinices.

El coronel actúa con la misma entereza; como Antígona, podría decir: "No he nacido para compartir odio, sino amor":

Vine. Llamé a los cuatro guajiros que se han criado en mi casa. Ob̆ligué å midijia Iśabel a que me acompañara. Así el acto se convierte en algo más familiar, más humano, menos personalista y desafiante que si yo mismo hubiera arrastrado el cadáver por las calles del pueblo hasta el cementerio. Creo a Macondo capaz de todo después de lo que he visto en lo que va corrico de este siglo. Pero si no han de respetarme a mí, ni siquiera por ser viejo, coronel de la república, y para remate cojo del cuerpo y entero de la conciencia, espero que al menos respeten a mi hija por ser mujer. No lo hago por mí. Tal vez no sea tampoco por la tranquilidad del muerto. Apenas para cumplir con un compromiso sagrado. Si he traido a Isabel no ha sido por cobardia, sino por una simple medida de caridad. Ella ha traído el niño (y entiendo que lo ha hecho por eso mismo) y ahora estamos aquí, los tres, soportando el peso de esta dura emergencia (15).

(14) Paul de Saint-Victor. Ob. cit., Tomo I, p. 474.

(15) La hojarasca. Edit. cit., pp. 27-28. 
En uno de sus monólogos, Isabel se ha réerido también a la actitud de soberbia desafiante que su padre adoptaba cada vez que hacía algo con lo cual no estarian de acuerdo los demás $\left({ }^{16}\right)$.

2.- Otro paralelismo evidente es el que corresponde a la situación de los personajes trágicos Polinices y Eteocles frente a la del médico y el sacerdote conocido en Macondo como El Cachorro. Estos últimos han llegado al pueblo el mismo dia, hace veinticinco años. Lejos de ver aquí una coincidencia gratuita, nos parece que el novelista quiso alegorizar en este hecho la relación de los hermanos en la tragedia. La llegada al pueblo viene a ser, por lo tanto, una forma de nacimiento común. Por otra parte, debe tenerse en cuenta que la impresión de un notable parecido físico entre el médico y El Cachorro se explicita claramente en la novela en más de una ocasión; de manera muy precisa, en dos momentos de los recuerdos del coronel:

- ¿Usted ha oido hablar de El Cachorro? - Le pregunté.

Respondió que no. Yo đije: "El Cachorro es el párroco, pero más que eso es un amigo de todo el mundo. Usted debe conocerlo"

-Ah, sí, sí, dijo él-. El también tiene hijos, ¿no?

-No es eso lo que me interesa ahora, dije yo. La gente inventa chismestal El cachorro porque to quieren mucho y hace lo posible por demostrar lo contrario. Pero allí tiene usted un caso, doctor. El Cachorro está muy lejos de ser un rezandero, un santurrón como decimos. Es un hombre completo que cumple con sus deberes como un hombre.

- Creo que El Cachorro va a ser santo, dije yo-. Y en eso también era sincero. "Nunca habiamos visto en Macondo nada igual. Al principio se le tuvo desconfianza porque es de aquí, porque los viejos lo recuerdan cuando salía a coger pájaros como todos los muchachos. Peleó en la guerra, fue coronel y eso era una dificultad. Usted sabe que la gente no respeta a los veteranos por lo mismo que respeta a los sacerdotes. Además, no estábamos acostumbrados a que se nos leyera el almanaque Bristol en vez de los Evangelios".

(16) Cf. Ibfdem. p. 33. 
Ahora estaba sonriente y escuchaba con una atención dinámica y complacida. Yo también me sentía entusiasmado. Dije: "Todavía hay algo que a usted le interesa, doctor. ¿Sabe desde cuándo está El Cachorro en Macondo?

El dijo que no.

- Llegó por casualidad el mismo día que usted - dije yo$\mathrm{Y}$ todavía algo más currioso: $\mathrm{Si}$ usted tuviera un hermano mayor, estoy seguro de que seria igual a El Cachorro. Físicamente, claro. (17)

El segundo momento clave alude a la única vez en que se encuentran El Cachorro y el médico:

El Cachorro habló muy poco en esa visita. Desde su entrada a la habitación parecía impresionado por la visión del único hombre que no conoció en quince años de estar en Macondo. Esa vez me di cuenta (y mejor que nunca, acaso porque el doctor se había cortado el bigote) del extraordinario parecido de esos dos hombres. No eran exactos, pero parecian hermanos. El uno era varíos años mayor, más delgado y escuálido. Pero había entre ellos la comunidad de rasgos que existe entre dos hermanos, aunque el uno se parezca al padre y el otro a la madre. Entonces me acordé de la última noche en el corredor. Dije:

-Este es El Cachorro, doctor. Alguna vez usted me prometió visitarlo.o(18)

Mientras Et Cachorro se integra y domina la vida del pueblo, el médico concita en torno suyo, cada vez más, esa sorda odiosidad que culmina en el repudio final y en la condenación. A la muerte de El Cachorro, ocurrida hace cuatro años, Macondo le rinde - como Tebas a Eteocles - los más conmovedores homenajes fúnebres. Monologa el coronel:

El Cachorro los tenía sometidos a una disciplina férrea. Incluso después de que murió el sacerdote, hace cuatro años - uno antes de mi enfermedad- se manifestó esa disciplina en la manera apasionada como todo el mundo arrancó las flores y los arbuistos de su huerto y los llevó a la tumba, a rendirle a El Cachorro su tributo final. (19)

(17) La holarasca. Edit. cit., pp. 101-102.

(18) La hojarasca. Edit. cit., p. 118.

(19) Ibidem. pp. 128-129. 
Sabemos ya cuál es la actitud de Macondo ante el médico. La relación entre el destino de éste y el de Polinices nos parece indudable.

3.- Situación de Ismena. Repuesta de su temor inicial, Ismena intenta reivindicar su parte en la acción de Antígona y afrontar también el castigo. Sin forzar demasiado el paralelismo, creemos que la primera actitud negativa de Ismena está representada en La hojarasca por el terminante rechazo de la mujer del coronel, Adelaida, a acompañarlo $\left({ }^{20}\right)$. El segundo momento, reivindicatorio, corresponde a la posición de Isabel, a pesar de que la adhesión de ésta hacia su padre aparece disminuida por la reserva y el miedo.

4.- Otras relaciones. Hay en La hojarasca algunos aspectos que contribuyen a fijar aún más la determinación del correlato que hemos propuesto.

La Antigüedad remota no concebía la separación del alma y la del cuerpo. El sepulcro era la casa de una nueva cxistencia. Se colocaban, pues, al lado del difunto sus vasos y sus armas; "a veces -dice Saint-Victor- se llegaba hasta a degollar sus caballos y sus esclavos para que el espectro del dueño estuviese rodeado de una servidumbre de fantasmas" ${ }^{21}$ ). En La hojarasca, un acto y una reflexión del coronel establecen una suerte de correspondencia con esta costumbre:

Busco en la oscuridad cle aquel baúl sin fondo sus baratijas dispersas، JEstáe sinu uave, en CeD otro rincón, con las mismas cosas que trajo hace veinticinco años. Yo recuerdo: Tenía dos camisas ordinarias, una caja de dientes, un retrato y ese vicjo formulario empastado. $\mathrm{Y}$ voy recogiendo estas cosas antes de que cierren el ataúd y las echo dentro de él. El retrato está todavia en el fondo del baúl, casi en el mismo sitio en que estuvo aquella vez. Es el daguerrotipo de un militar condecorado. Echo el retrato en la caja. Echo la dentadura postiza y finalmente el formulario. Cuando he concluido hago una señal a los hombres para que cierren el ataúd. Pienso: Ahora está de viaje otra vez. Lo más natural es que en el último se lleve las cosas que le acompañaron en el penúltimo. Por lo menos, eso es lo más natural. Y entonces me parece verlo, por primera vez, cómodlamente muerto.

Cf. Ibídem. pp. 124-125

(21) Paul de Saint-Victor. Ob. cit., Tomo I, p. 466. 
Examino la habitación y veo que se ha olvidado un zapato en la cama. Hago una nueva señal a mis hombres, con el zapato en la mano, y ellos vuelven a levantar la tapa en el preciso instante en que pita el tren, perdiéndose en la última vuelta al pueblo (22).

Nos parece también altamente significativa la manera cómo el médico decide suicidarse. En el ámbito de la tradición -y desde los tiempos homéricos - la muerte por ahorcamiento era considerada infamante o propia de los impuros. Es por eso que se ha ahorcado Yocasta. En Edipo rey, éste expresa que sus crímcnes "son mayores que los que se expian con la estrangulación” ( $\left.{ }^{23}\right)$. Ismena, al recordarle a Antígona la su ma de las desgracias familiares, alude igualmente a este hecho:

¡Ay de mí! Reflexiona, hermana, que nuestro padre murió aborrecido e infamado, después que, por los pecados que en sí mismo había descubierto, se arrancó los ojos él con su propia mano. Támbién su madre y mujer - nombres que se contradicen- con un lazo de trenzas se quitó la vida. Y como tercera desgracia, nuestros dos hermanos en un mismo día se degüellan los desdichados dándose muerte uno a otro con sus propias manos.

$\mathrm{Y}$ ahora que solas quedamos nosotras dos, considera de qué manera más infame moriremos si con desprecio de la ley desobedecemosta orden y autoridad del tirano (24).

$$
\text { "Jorge Puccinelli Converson }
$$

La presencia de la fatalidad en La hojarasca y el sentimiento de expiación de oscuras culpas reconocidas por el coronel, remiten también el sustrato trágico que da sentido a la novela. Recuérdase el final de Antígona:

Coro.-Pues no pidas nada; que de la suerte que el destino tenga asignada a los mortales, no hay quien pueda evadirse.

Creonte.- Echad de aquí a un hombre inútil, que ¡ay, hijo! te maté sin querer; y a ésta también. ¡Pobre de mí! No sé hacia qué lado deba inclinarme, porque todo lo que tocan mis manos se vuelve contra mi; sobre mi cabeza descargó intolerable fatalidad. (25)

(22) La hojarasca. Edit. cit., p. 29.

(23) Sofocles. Edipo rey. Edit. cit., p. 120

(24) Sofocles. An:igona. Edit. cit., p. 178.

(25) Id., Ibidem, p. 212. 
En algunas meditaciones del coronel, se siente como una resonancia de ese desolado final de la tragedia:

... lo que venía después estaba más allá de nuestras fuerzas, era como los fenómenos atmosféricos anunciados en el almanaque, que han de cumplirse fatalmente.

... algo me indicaba que era impotente ante el curso que iban tomando los acontecimientos. No era yo quien disponía las cosas en mi hogar, sino otra fucrza misteriosa, que ordenaba el curso de nuestra existencia y de la cual no éramos otra cosa que un dócil e insignificante instrumento. Todo parecía obedecer entonces al natural y eslabonado cumplimiento de una profecia.

... otro capítulo de la fatalidad había empezado a cumplirse desde hacía tres meses. (26)

La hojarasca es para nosolros, desde su título, una requisitoria social y moral. La palabra apunta al residuo del odio, la incomunicación y el resentimiento que ha dejado en el mítico pueblo de Macondó el paso de la compañía bananera establecida allí por muchos años, y que ahora lo ha abandonado. Para iluminar esa rcalidad caótica -acaso para exorcizarla- Gabriel Garcjál Márquez recurfié a das viejas fuentes literarias y, como es necesario hacerlo, las asumió en plenitud. La elección mejor déE pasadónsustentá, de este modo, la visión de su mundo concreto y actual.

(26) La hojarasca. Edit. cit., pp. 104 y 106. 


\section{CONTRIBUCION A LA BIBLIOGRAFIA DE GABRIEL GARCIA MARQUEZ}

\section{OBRAS.*}

La hojarasca. (Novela). Bogotá - Colombia, Ediciones - S.L.B., 1955. 137 pp.

Monólogo de Isabel viendo Hover en Macondo. 「Cuento †. En MITo. Revista Bimestral de Cultura. Bogotá, año I. N: 4, octubre-noviembre 1955. pp. 221-225. Tb. en Ricardo A Latchmar. Antologia del cuento hispanoamericano contemporáneo (1910-1956). Santiago de Chile, Zig-Zag, 1958. pp. 241245.

El coronel no tiene quien le escriba. (Novela). En MITO. Bogotá, año IV, Nọ 19 mayo-junio de 1958. pp. 1-38.

El coronel no tiene quien le escriba. Medellin, Aguirre Editor, 1961. 90 p. ímpreso en Buenos Aires-Argentina, por Américalee 7.

"Dos o tres cosas sobre la novela de la violencia". En TABLA REDONDA. Caracas, Números 5-6, abril-mayo de 1960. pp. 19-20.

Los funerales de la Mamá Grande. 「Cuentos 1. Xalapa, México, Universidad Ve:acruzana, 1962. 151 p. (Ficción, 34).

Contiene: La siesta del martes; Un dia de estos; En este pueblo no hay ladrones; La prodiglosa tarde de Baltazar; La viuda de Montiel; Un día después del sábado; Rosas artificiales; Los funerales de la Mamá Grande.

La mala hora. 「Novela 7. (Premio Literario ESSO 1961). Madrid, Talleres de Gráficas "Luis Pérez", 1962. 224 p.

La mala hora. México, Ediciones ERA, S.A., 1966. 198 p. (Blblloteca ERA). $\Gamma$ "La primo:a vez que se publicó La mala hora, en 1962, un corrector de prucbas se permitió cambiar ciertos términos y almidonar el estilo, en nombre de la pureza del lenguaje. En esta ocasión, a su vez, el autor se ha permitido restituir las incorrecciones idiomáticas y las barbaridades estilistica, en nombre de su soberana y arbitraria voluntad. Esta es, pues, la primera edición de La mala hora. El autor" 7 .

Clen años de soledad. 「Noyela 7. Buenos Aires, Editozial Sudamericana, 1967. 351 p. (Colección Grandes Novelas).

\section{REFERENCIAS Puccinelli Converson}

Alvarez, Federico (F.A.). Los libros abiertos. "Gabriel García Márquez, Los funerales de la Mamá Grande 「...7”. REVISTA DE LA UNIVERSIDAD DE MEXICO. México, Vol. XVII. No 3, noviembie de 1962. p. 31.

Alvarez destaca los valores de expresividad, tensión dramática e impecable sobriedad del lenguaje que caracterizan este libro de G.G.M. Al final de su nota, se refiere a las influencias de Joyce, Faulkner y Virginia Woolf, -econocidas por el autor, indicando la propiedad y la eficacia con que García Márquez ha asumido aquí esas influencias, particularmente la de Faulkner.

Anónimo. 'Ta hoiaracca -Gahriel García Márqucz「...7”. MITo. Bogotá, año I, No 1, abril-mavo, 1955. p. 52.

Anónimo. "Cien años de un puebln". visInN. Revista Internacional. Santia. go de Chile. Empresa Editora Zig-Zag. S.A. Vol. 33, No 4, 21 de iulio de 1967 pp. $27-29$.

Es una entrevista realizada en México. con motivo de la publicación de Cien años de soledad. Las resnuestas de G.M. se refieren a su método de trabjo. a su concepción de la novela, a la experiencia lograda como escritor de muiones para el cine v a la situación del rénero novelístico en la literatura latinoamericana. "En realidad - dicc G.M.-, lo único nuevo

- Tndicamos anuf las nrimeras ediciones. v cólo en casos especiales (El coronel no tiene auien le escrlba v Is mala hornl remitimos a otras noeteriores. El artículo cobre la novela de la violencia. a nesar de su carácter ne-indistico, nos narece necesario para conocer las ideas de García Márquez sobre el temn. 
que hay en la novela latinoamericana, es $\Gamma \ldots\rceil$ Mario Vargas Llosa". Piensa que la obra del escritor peruano es la que ha provocado el interés actual del publico europeo y norteamericano por la novela de este continente, que cuenta con autores prestigiosos desde hace mas de veinte años.

Arango Ferrer, Javier. "Medio siglo de litcratura colombiana" En Panorama das Ilteraturas das Américas (De 1900 a actualidacle). Angola, Edicao do Municipin de Nova Lisboa. 1958. Volunie I. pp. 375-376.

Dorfman. Ariel. "La vorágine de los fantasmas". ERCILLA. Santiago de Chile, No 1.617, 19 de junio de 1966 p. 34.

Breve anślisis de La hojarasca y de El coronel no tlene quien le escriba.

Fuentes, Carlos. Versiones. "García Márquez. Clen años de soledad". LA CULTURA EN MEXICO. Suplemento de iSiempre! México, No 228, 29 de junio de 1966 . p. VII.

Comentario de gran interés sobre las primeras ochenta cuartillas de la novela Cíen años de soledad, inćdita a esa fecha. En él. Fuentes analiza el carácier antimaniqueista y la función del mito en el nuevo arte y la nueva literatura latinoamericanos $\%$ en especial, en la producción última de G.G.M.

「Hai'ss, Luis]. "América, con todo. La hojarasca, por Gabriel García Márquez, Arca, Montevideo, 1965; 127 páginas 「... 7". PRIMERA PLANA. Buenos Aires, año IV, No 160,30 de noviembre al 6 de diciembre de 1965. D. 55.

Aunque este comentario aparece sin firma del autor, es casi seguro que pertenece a Luis Harss. Varias de las ideas críticas que aquí se desarrollan se encuentran también en su trabajo "Gabriel García Márquez, o la cuo:da floia"

Harss, Luis. "Gabriel Garcia Márquez, o la cuerda lloia". En Los nuestros. Buenos Aires, Editorial Sudamericana, 1966. (Colección "'Perspectlvas"). pp. 381-419. Reproducido en MUNDO NUEVO. Revista de América Latina. París, No 6, diciembre 1966. pp. 63-77.

Harss empieza por situar al escritor en el contexto de la literatura colombiana: proporciona luego algunas noticias biográficas, y emprende -apoyado en testimonios del propio novelista - el estudio pormenorizado de los temas estructuras. procesos de influencias, problematización del lenguaje, recursos expresivos, asunción de los mitos, p:oveccićn simbólica y trascendencia de su narrativa. Es un trabajo ensavístico de importancia, pero cuyo mérito se ve disminuido por las frecuentes inexactitudes del autor al referirse a las ob:as de G.M.

Kirsner, Robert. "Four colombian novels of 'violencia' ". HISPANIA. U.S. A., Vol. XLIX, No 1, March, 1966. pp. 70-74.

Se refiere, a través de un enfoque predominantemente sociológico, y sin mayor pofundidad c-ítica, a las siguientes novelas: Lo que el ciclo no perdona, por Ernesto León Herrera; El Cristo de espaldas, por Eduardo Caballero Calderén; La mala hora, por Gabriel García Márquez, y El día señalado, por Manuel Mejía Valleio.

Latcham, Ricardo. Crónica literaria. "El coronel no tlene quien le escriba, por Gabriel García Márquez「... $7^{\prime \prime}$. La Nación. Santiago de Chile, 3 de diciembre de 1961. p. 2 .

Con el título de "Denuncia y violencia en la novela", este trabajo apareció en la revista MARCHA, de Montevideo, No 1090, 29 de diciembre de 1961, precedido de una breve nota sobre la novelística colombiana actual y de un análisis de la obra de Eduardo Santa. El Girasol. Esta versión es la que se incluye en Ricardo A. Latchman. Antología. Crónica de varia lección. Santiago de Chile, Zig-Zag, 1965. (Colección Antologías). pp. $100-106$

Latchman. Ricardo. Crónica literaria. "Gabriel García Márquez. La mala hora. (Madrid, 1962)". La Nación. Santiago de Chile, 31 de mayo de 1964. p. 5 . 
Loveluck, Juan. "Gabriel García Márquez, narrador colombiano". DUQUESNE HISPANIC REVIEW. U.S.A., año V, No 3, 1967. pp. 135-154. Hay sobretizo.

El estudio de Juan Loveluck, de consulta indispensable, se refiere casi en su totalidad a La hojarasca, aunque el autor considera siempre la pers. pectiva que otorgan los cuatro libros publicados por G.G.M.

Los temas del lúcido tratamiento desarrollado por Loveluck son los siguientes: "Ambito de La hojarasca"; "Macondo como abreviatura del mundo: a) Los personajets 'constante', b) Los motivos 'flotantes', c) El afán por fundir pasado y presente, en una línea de vigencia continua, y c) La elección y fijacićn de un lugar como 'abreviatura' o 'cifra perfecta' del mundo"; "Disposición temporal de La hojarasca".

Márquez, Manuel. "Los padres terribles". Epoca. Montevideo, 16 de febraro de 1966. p. 10.

Se trata de una crítica a la edicí́n uruguaya de La hojarasca (Arca, 1965), en la que el autor de la nota intenta puntualizar el alcance de la influencia de Faulkner, que le parece insuficientemente asimilada en esta obra. Algunas observaciones del comenta:ista, como aquellas que señalan "la inexorable flaqueza, en G.M., de invención creadora" o "la falta de pasión de G.M. por su mundo", no sólo no se cumplen en La holarasca, pese a sus limitaciones, sino que resultan decididamente incomprobables en el resto de su produccí́n que, a esta altura, el crítico ya debería tener presente en su coniunto.

Martinez, Tomás Eloy (T.E.M.). Libros. "América": La gran novela. Gabriel Márquez: Cien años de soledad". PRIMERA PLANA. Buenos Aires, año V, No 234,20 al 26 de junio de 1967 pp. 54-55.

T.E.M. señala que Clen años de soledad resume, mejor que ninguna otra novela latinoamericana actual, las diversas corrientes narrativas propuestas por la tradición. Puntualiza la eficacia con que el novelista asedia la realidad en sus más diversos niveles a t:avés de la historia completa de Macondo, v la provección última de la obra, que aparece como "una metáfora minunciosa de toda la vida americana, de sus peleas, sus malos sueños y sus frustraciones". Para América latina, la novela de G.G.M. tiene, por lo tanto. el carácter de un génesis, de una apertura hacia las fo-mas más profundas de su existencia. El penetrante comentario de T. E.M. se refiere también, brevemente, a los peligros de la uniformidad de la escritura en Cien años de soledad, $\mathrm{Y}$ pone de relieve el modo cómo el autor logra superarlos.

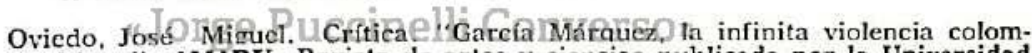
biana" AMARU. Revista de artes y ciencias publicada no- la Universidad Nacional de Ingeniería. Lima, No 1, enero 1967. pp. 87-89.

En la primera parte de su crítica, Oviedo hace un recuento de la producrićn general de G.G.M.. que ve hilvanada lomo un "saga" colombiana desprendida de un mundo mitológico-real, y que constituye, en su. ma. una sola metáfora de sn país. Analiza luego la violencia como asunto prinripal de las ficciones de G. G M. La seruinda parte, más extensa, es un examen de La mala hora, en el que Oviedo verifica la formulación anterior; concluye cstableciendo que La mala hora es una novela de clima, no de acción ni de personajes.

Rama. Angel. Letras colombianas. "García Márauez: la violencia americana" MARCHA. Montevideo, № 1201, abri1 17 de 1964. pp. 22-23.

Es un estudio fundamental - que se refiere sobre todo a la obra novelística de G.G.M - desarrollado con gran coherencia y exactitud, escialmente en sus observaciones acerca de la unidad de la cosmovisión de G.G.M., de la concreción narrativa de los asuntos y del sentido de las relaciones simbólicas que se proponen en esas novelas.

Rodríguez Fernández, Mario. "Clen años de soledad de Gabriel García Márauez". La Nación. Santiago de Chile, 20 de agosto de 1967. Suplemento dominical, p. 5 .

El artículo de Mario Rodríguez, a pesar de su brevedad, insinúa las notas esenciales de esta novela de G.G.M., al entenderla como reveladora de la condición caótica, babilćnica, alucinada, trágica y violenta de la realidad y el ser histórico colombianos. 
Schóó, E.nesto. "Los viajes de Simbad Garcia Márquez". PRIMERA PLANA. Buenos Aires, año V. No 234, 20 al 20 de junio de 1967. pp. 52-54.

Es un reportaje que contiene an:ecedentes biográficos valiosos, iluminadores de diversos aspectos de la formacion del escritor, de su sistema de trabajo y de su posición actual frente a la literatura.

Téllez, Hernando. Libros. "Gabriel Ga-cia Marquez: La mala hora". CUADERNOS. Revista publicada bajo ei patrocinio del Congreso por la Libertad de la Cultura. Paris, Nọ 81 , febrero 1964. pp. 87.88 .

Volkening. Ernesto. "Gabriel Garcia Márquez o el trópico desemb:ujado". ECO. Revista de la Cultura de Occidente. Boguiá, Tomo VII, 1963, No 40. pp. $275 \cdot 293$.

Este ensayo de Volkening sitúa con claridad las notas que particularizan la producción cuentistica de G.G M. entre la que incluye El coronel no tlene quien le escriba. El critico establece que la relación de influencia de Faulkner en la obra del auto- colombiano sólo debe so: vista en el aspecto temáticn y no en e! esti!o ni en los medins expresivos. En este punto, destaca las características relevantes de sobricdad descriptiva de las narraciones de García Márquez.

Las observaciones de Volkening son muy estimables, especialmente en lo que se refiere a la función de lo grotesco como un modo de acercarse al lado trágico de la existencia, y en sus notas sobre "lo fragmentario" en los cuentos, recurso que. a su iuicio, responde a una visićn del mundo como problemático e inconcluso.

Volkening. Ernesto. "A propósito de La mala hora". ECo Bogotá, Tomo VII, 1963. No 40 pp 294.304. Renroduciclo en el Magazine dominical de El Espectador. Bogotá. 6 de octubre de 1963. pp 8-9-E, con el tftulo de 'La habitual maestría de García Márquez. A propósito de La mala hora'.

En su análisis de La mala hora. el crítico muestra las debilidades de construcción de la novela que se disuelve en una serie de episodios ca. rentes de concatenación. sin igualar la densidad de los relatos anteriores del autor. Señala también aue lo "f-ammentario" - que constituve uno de Ins atractivns más notahies de los cuentos- se asentín anulf en detri-

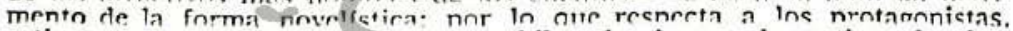
estimn aue son muv norne les alle exhihen la riourga de matiese. la nlas. tiridar v la reriedumbre nur enrnrende en los nerenmaiec do Fi coronel no tlene quien le escriba $y$ de Los funcrales de la Mamá Grande. 